\title{
Caminhos e Paradas. Perspectivas sobre o território Laklãnõ (Xokleng)
}

\author{
Juliana Salles Machado*
}

MACHADO, J.S. Caminhos e Paradas. Perspectivas sobre o território Laklãnõ (Xokleng). R. Mus. Arq. Etn., 27: 179-196, 2016

Resumo: Há 100 anos do primeiro aldeamento forçado dos Xokleng/Laklãnõ do Estado de Santa Catarina vemos um momento de intensa movimentação social e política entre esta população indígena. Empenhados em um projeto de fortalecimento de sua identidade étnica, os Laklãnõ (Xokleng) têm buscado na história, no passado e na memória um caminho para o seu futuro. Desde pelo menos a década de 1970, esta população indígena tem participado na produção de conhecimento científico como interlocutores em diversas pesquisas. Sua memória é tecida a partir de fios da história oral juntamente com discursos acadêmicos oriundos de diversas disciplinas ao longo desta trajetória de contato. Hoje inseridos no âmbito acadêmico eles vem construindo um projeto cultural para o seu povo baseado em um complexo emaranhado de saberes e conhecimentos que extrapolam as divisas entre local-global, êmico-ético, saber nativo - conhecimento científico. Neste trabalho pretendo refletir sobre nossas próprias construções e práticas na pesquisa arqueológica a partir dos trabalhos feitos por acadêmicos indígenas sobre o eixo do passado-presente.

Palavras-chave: Laklãnõ (Xokleng); Memória; Identidade étnica; Saberes; Acadêmicos indígenas.

\begin{abstract}
A pesar de não ter contornos bem definidos, o território tradicional dos grupos Laklãnõ (Xokleng), conforme aponta Santos (1973), compreendia à época do contato as áreas de Mata Atlântica no litoral e na encosta de serra, bem como as bordas do planalto recoberto por Mata de Araucárias na porção sudeste e sul do Brasil. Os limites do território tradicional deste povo ficaram conhecidos na literatura como os seguintes: ao norte, em Paranaguá no Paraná; ao sul nas proximidades de Porto Alegre e à noroeste, nas florestas nas proximidades do Rio Iguaçu e campos de
\end{abstract}

(*) Professora Visitante do Programa de Pós-Graduação em História, Departamento de História da Universidade Federal de Santa Catarina. Pesquisadora do LEIA-UFSC.

<julianasallesmachado@gmail.com>
Palmas (Santos 1973, Noelli 1999-2000, Lavina 1999, Pereira 1998).

Os assentamentos arqueologicamente conhecidos relacionados ao período pré-colonial associados aos Jê do sul, família linguística do qual esta população indígena é falante, variam de aldeias à céu aberto, abrigos-sob-rocha, sambaquis fluviais e costeiros e estruturas subterrâneas (Piazza 1967; Eble 1973; Schmitz et al. 2009; Noelli 1999-2000, 2004; Farias 2005; Cortelleti 2012). Tal diversidade de contextos foi interpretada por Noelli (1999-2000: 242) como relacionada a um "processo contínuo de guerra e desterritorialização [que] causou mudanças significativas na cultura material, nos padrões de adaptação e na organização social e política" destes povos. Atualmente, apesar da grande quantidade de pesquisas arqueo- 
lógicas e históricas nesta região, não temos dados suficientes para correlacionar vestígios arqueológicos à população Laklãnõ Xokleng (Noelli 1999-2000, 2004; Silva e Noelli 1996). No contexto do sul do Brasil, a grande maioria dos vestígios cerâmicos é identificado através de fases e tradições arqueológicas definidas no âmbito do PRONAPA (Schmitz et al 2009; Piazza 1967; Eble 1973; Farias 2005), tendo sido mais recentemente associadas à duas grandes familías linguísticas: Jê e Tupi-Guarani. Os vestígios cerâmicos associados ao tronco Tupi, com origem provável da Amazônia são mais diretamente associados aos povos Guarani, falantes de língua homônina. No caso dos Jê, localmente chamados de Jê Meridionais ou Jê do sul, no entanto, os povos conhecidos etnograficamente e através de documentações históricas são os Kaingang e os Xokleng, estes últimos, atualmente autonomeados Laklãnõ (Gakran 2005; Machado 2015). Apesar de constituirem povos distintos e atualmente ser possivel identificar seus objetos particulares, o repertório material produzido por estes povos em tempos pré-coloniais apresenta semelhanças tecnológicas (Silva e Noelli 1996), o que aliado a escassez de pesquisas sistemáticas sobre o tema, acarreta na atual dificuldade de diferenciar estes povos numa escala temporal mais ampla (Noelli 1999/2000). Apesar desta dificuldade alguns autores apresentam hipóteses que podem nos ajudar a melhor compreender tais associações (Reis 2002; Farias 2005; Schmitz et al 2009; Corteleti 2012; De Masi 2006).

Os Laklãnõ (Xokleng) ficaram conhecidos por seu contato tardio, que ocorreu apenas no século XIX, quando confrontavam as fazendas de gado que adentravam cada vez mais seu território. O conflito sobre as terras foi marcado pela extrema violência, especialmente pelas ações dos chamados bugreiros nesta região (Santos 1979, 1973, 1965). À época do contato este povo ficou conhecido como caçador-coletor com alta mobilidade, já que sua permanência em pequenas aldeias e acampamentos consistia em poucos dias e não foram reconhecidas áreas de plantio, assim como a pouca produção cerâmica. Contudo, alguns autores acreditam que esta população indígena assumiu tal padrão de assentamento e mobilidade pouco tempo antes do contato ${ }^{1}$ (Noelli 1999/2000; Cortelleti 2012; Farias 2005; Claudino 2011), impulsionado por processos de guerra e desterritorialização. Nesta hipótese, os Laklãnõ (Xokleng) teriam um passado marcado por aldeias de maior permanência com a prática da agricultura e produção cerâmica (Noelli 1999/2000).

Também as informações etnográficas de Silvio Coelho dos Santos (1973) indicam que "outrora" este povo praticava agricultura em áreas do planalto e que, devido à dinâmica colonial, posteriormente os Laklãnõ (Xokleng) teriam adotado a caça e a coleta como principal forma de subsistência.

Entretanto, a visão mais difundida acerca da forma de prover a subsistência do povo Laklãnõ (Xokleng) no passado é a constante nos relatos de Eduardo Hoerhann (1921):

\section{É uma tribu que vive essencialmente da} caça, e, portanto nomade, sempre em transito pelas florestas á procura e perseguição da mesma. Preferem a anta, não só pelo sabor da sua carne, como pela quantidade da carne. Caçam. na dos seguintes modos: procuram rastro fresco no qual soltam os seus cães, acompanhando-os na carreira até o levante da anta. Orientam-se em seguida da direcção tomada pela mesma, que sempre segue os seus habituaes carreiros, por elles conhecidos, atalham pela floresta, esperando adiante a sua passagem. Atropelada pelos cães, vem a anta em vertiginosa corrida, sendo então atacada e morta a lançassos. Admiravel a segurança do primeiro golpe, que nunca falha, fazendo desmunhecar instantaneamente o animal que é então carregado (HOERHANN 1921 apud.VIEIRA 2004: 20).

Informações como esta vem sendo utilizadas como base para a escrita da história dos Laklãnõ (Xokleng) (Wittman 2007), inclusive na formulação de modelos arqueológicos que

1 Vale ressaltar, no entanto que tais associações são feitas para os Jê do sul como um todo, que, como mencionei anteriormente, englobam tanto Kaingang quanto Laklãnõ/Xokleng, sendo que apenas em alguns exemplos são apontados correlações específicas para os Laklãnõ/Xokleng. 
pretendem investigar um passado mais remoto (Lavina 1994; Claudino 2011).

\section{Território e Mobilidade Laklãnõ (Xokleng)}

Lavina (1994), com base em documentação etnohistórica, caracteriza esta população como caçadora-coletora com movimentação sazonal por um amplo território a fim de prover a sua subsistência. Este autor identifica nas práticas Laklãnõ (Xokleng) uma alta mobilidade relacionada à exploração de diferentes ambientes visando obter recursos alimentícios em períodos distintos do ano, o que é definido pelo autor como um "movimento pendular" entre o vale e o planalto. Tal deslocamento implicaria na utilização de dois tipos de assentamentos no seu território tradicional: um mais fugaz, quando se tratava de obter alimentos através da caça e da coleta na área de Mata Atlântica; e o outro de maior duração, quando se tratava de explorar os frutos dos pinheirais e de caçar os animais que recorriam a Mata de Araucária.

Por outro lado, congregando dados históricos e arqueológicos, Farias (2005) e De Masi (2006) inferem a existência de assentamentos estáveis para grupos Laklãnõ (Xokleng). No mesmo sentido que Lavina (1994), Farias (2005: 119138) sugere que esta população se movimentaria no ambiente de Mata Atlântica, transitando entre áreas altas e baixas. No entanto, diferente do primeiro autor, ressalta que apenas eventualmente indivíduos de alguns grupos recorreriam à Mata de Araucárias a fim de se abastecer de grandes quantidades de pinhão, alimentos que eram transportados até os acampamentos maiores localizados em terras menos elevadas. Este modelo pressupõe que os Laklãnõ (Xokleng) possuiriam assentamentos estáveis, situados em áreas de meia encosta próximas a nascentes e a banhados, onde as famílias viveriam em grandes cabanas. Em locais mais distantes, interligados ao acampamento principal por meio de trilhas, existiriam pequenas cabanas utilizadas para abrigar transeuntes e grupos de caçadores.

Os modelos de mobilidade propostos pelos diversos autores está pautado, em grande parte à alta mobilidade atribuída à população Laklãnõ
(Xokleng). Isto se deve, em grande parte, aos registros à época do contato com a sociedade não-indígena, como podemos ver em alguns trechos apresentados abaixo:

"Poucos dias se demoram no logar onde fazem aldeamento, mas vão mudando de pouso, ao passo que lhes escasseia a caça. As palhotas são deitas de paus e cobertas de ervas, nem se incomodam a desmanchá-las, quando mudam de residência. Durante o dia espalham-se pelas mattas em procura de alimento; a noite juntam-se todos no rancho (...)" (Tavares 1910: 282-283 apud Lavina 1994: 53).

"Vivem em continua emigração de serra acima para serra abaixo, conforme é tempo do pinhão na zona do Planalto ou de outros fructos nas zonas marítimas. Não só os frutos procuram, nestas correrias, como a caça que com elles apparece mais fácil e abundante". (Boiteaux 1911:71 apud Lavina 1994)

"uma tribo que vive essencialmente de caça e, portanto, nômade, sempre em trânsito pelas florestas, a procura e perseguição da mesma" Paula (1924: 119)

"Nos mezes de abril, maio e junho seguem, em grupos, para a região dos pinheiraes. Escalam ahu os pinheiros por meio de uma peia e de uma laçada feita de trama de taquara, que passam pelo tronco do pinheiro. Enfia-se o indio na laçada, que passa por debaixo dos braços, e contra a qual firma o corpo, apoiando os pés contra o pinheiro, ligados pela peia. Deste modo alternativamente, ora firme nos pés levanta a laçada, ora firme na laçada erque os pés e com rapidez e destreza admiraveis escalam o tronco erecto da Araucarua até a sua copa. Ahi avançam pelos galhos e agitand-os fortemente fazem cahir as pinhas" (Paula 1924: 121)

Estes documentos, entre muitos outros ${ }^{2}$ levaram pesquisadores, como Lavina (1994), a propor modelos de nomadismo para esta

2 Para uma análise historiográfica dos documentos relacionados à população Laklãnõ (Xokleng) ver Wittman 2007 
população, conforme expresso pelo autor: "O nomadismo estacional é uma característica essencial dos Xokleng, estando este nomadismo ligado às atividades de caça e coleta, que obrigam o grupo a um deslocamento mais ou menos constante dentro do território por eles ocupado" (p.55).

Já De Masi (2006: 47-49), analisando a ocupação pré-colonial do baixo Rio Canoas, acredita que a população que viveu preteritamente no local possuiria um assentamento estável onde fazia uso da horticultura ligada ao cultivo de milho e de legumes. A presença de pontas de projétil sugeriria a realização da caça, enquanto as estruturas subterrâneas seriam, para o autor, silos relacionados a coleta. De Masi associa estes contextos arqueológicos à população Laklãnõ (Xokleng) e propõe que o assentamento destes grupos envolveria espaços destinados à residência (sítios cerâmicos a céu aberto), a estocagem de alimentos (estruturas subterrâneas), ao cultivo de plantas (sítios líticos a céu aberto com grandes bifaces), aos preparativos para caça (sítios líticos á céu aberto com pequenos bifaces) e a atividades cerimoniais (estruturas anelares) e/ou funerárias (estruturas anelares com montículos).

Para Noelli (2004: 26-27), de um modo geral, os grupos humanos relacionados ao chamado Jê do Sul, eram agricultores (com plantio de milho, mandioca, amendoim, feijão, cará) que também praticavam a caça generalizada, a pesca e a coleta (principalmente de pinhão, palmito, insetos e mel), bem como o manejo agroflorestal. Teriam ocupado ambientes de Mata de Araucárias e de Mata Atlântica. Confeccionavam um tipo de cerâmica peculiar, com pequenas dimensões e pouca decoração, de coloração escura (negra/cinza), marrom ou avermelhada. Sepultavam os mortos em montículos funerários ou os cremavam.

Além da ocupação das estruturas subterrâneas, entendidas como um indicador de sedentarismo por Noelli (1999/2000: 243), os grupos Jê do Sul deixaram evidências de seus antigos assentamentos em sítios a céu aberto, nos abrigos sob rocha e em camadas superiores de sambaquis (Fossari 2004). Estabeleceram-se, assim, nas terras altas do planalto meridional, em áreas da encosta da serra e na planície litorânea.
Os registros arqueológicos relativos aos Jê do sul (aqui inclusos Kaingang e Laklãnõ/ Xokleng) indicam uma grande variabilidade de contextos, atribuída a sucessivos processos de invasão e conquista de seu território. Em seu modelo para os Jê do sul, Noelli distingue três grandes movimentos territoriais na região sudeste e sul brasileira. $\mathrm{O}$ primeiro teria ocorrido entre 2.000 e 1.000 AP entre os Guarani, movimento que teria "empurrado-os" para longe das proximidades dos grandes rios e principais afluentes "confinando-os nas terras mais altas e frias da região sul" (1999/2000: 241). Em um segundo momento, há aproximadamente 700 $\mathrm{AP}$, eles teriam sido novamente impulsionados pelos Guarani, desta vez obrigando-os a sair do litoral, em direção à parte alta do planalto sul-brasileiro. Já a última pressão estaria relacionada aos europeus, que a partir de do século XVI venceram os Guarani do litoral, gerando uma nova acomodação territorial aos Jê do sul. No entanto, já no XVIII, quando há informações etnohistóricas que nos permitem atribuir dados específicos a uma ocupação pela população Laklãnõ (Xokleng), este povo tornaria-se o principal alvo da colonização européia, guerra que culminou no embate cruel das frentes de colonização do século XX, quando os Laklãnõ (Xokleng) foram quase totalmente exterminados. Tal trajetória acarretou em "uma drástica mudança na configuração demográfica e no tamanho dos territórios" (Noelli 1999-2000: 242).

\section{Os caminhos do andar Laklãnõ (Xokleng)}

Conforme apontamos, as informações acerca do passado dos Laklãnõ (Xokleng) são, no mínimo, diversas. Temos dados que os associam à populações agricultoras oriundos do planalto central brasileiro e indicadores de sua prática de manejo agroflorestal em larga extensão territorial associado a ciclos de plantio, deslocamentos e manejo, assim como modelos associados à sua alta mobilidade, predominância de coleta e caça e formas de ocupação que foram chamadas de nômades. A leitura que se faz destes dados geralmente é de 
contraposição, tratando-os como formas sociais antagônicas entre populações horticultoras, sedentárias com a produção de cerâmica e caçadores-coletores com alta mobilidade associados exclusivamente à produção de vestígios líticos. Neste artigo, buscarei compreender os dados apontados não como formas antagônicas, mas na tentativa de re-pensar como estes indicadores arqueológicos e etnobotânicos podem estar nos indicando uma forma específica de mobilidade, que pode estar atrelada à períodos históricos específicos, mas também à uma organização social particular.

Para refletir sobre isto, gostaria de retomar alguns dados acerca do território Laklãnõ/ Xokleng. Se utilizarmos o mapa de localização dos embates entre colonizadores e Xoklengs à época do contato (Lavina 1994; Cortelleti 2012 e Wittman 2007), teríamos hipoteticamente uma área total de $82.500 \mathrm{~km}^{2}$. Este cálculo leva em conta a dispersão dos registros de conflito entre os Laklãnõ (Xokleng) e os brancos na época do contato, incluindo portanto de Curitiba a Porto Alegre no eixo Norte-Sul e da costa às bordas dos planaltos no eixo Leste -Oeste). Se nos restringirmos ao Vale do Itajaí no estado de Santa Catarina, minha área atual de pesquisa e local apontado por várias fontes históricas como um local de concentração desta população indígena, teríamos uma área aproximada de $15.000 \mathrm{~km}^{2}$. Ainda que sejamos cautelosos sobre o significado desta área de dispersão, já que aqui estão sendo sobrepostas informações de diversos "bandos", enquanto que as projeções territoriais de caçadores coletores em geral baseiam-se em um bando ou grupo familiar específico, trata-se de uma área bastante extensa.

Utilizando os documentos etnohistóricos podemos citar dados acerca das formas de deslocamento dos indivíduos e famílias. Lavina (1994) nos indica que dentre um bando familiar, de 2 a 8 famílias dividiam-se para diferentes partes do território, buscando assim intensificar a caça e a coleta, tanto vegetal como animal. Tais pequenos grupos se encontravam novamente para festividades e ataques a colonos, conforme nos indicam vários documentos, como os citados abaixo:
- Paula (1924: 128): "O grande grupo só se reunia para a festa de perfuração dos lábios das crianças do sexo masculina, uma vez ao ano", e as festas eram realizadas "todos os anos em fins de dezembro a janeiro". Entre outubro e o inverno (abril, maio e junho) os grupos se deslocavam para as matas de araucária das bordas do planalto meridional para coleta do pinhão e para caçar animais atraídos $\grave{A}$ região por estes frutos (Paula 1924 apud Lavina 1994)

- Entes (1929): "após um dia de caminhada, levantavam ranchos em locais ricos em caça e lá poderiam ficar várias semanas. Em acampamentos mais estáveis, como aqueles realizados para as festas de perfuração de lábios das crianças, os acampamentos eram cercados de estacas para defesa e trincheiras eram construidas".

Os documentos históricos indicam portanto mobilidade, mas também estabilidade. Indicam dispersões, mas também agrupamentos e uma análise mais detalhada e minuciosa poderia nos indicar com maior clareza a dinâmica dessas populações à época do contato.

Há dados arqueológicos para grande parte desta região, no entanto falta uma compreensão regional de suas relações. Dentre os vestígios associados aos povos Jê, temos indicadores de sua associação a uma variabilidade de sítios (sítios à céu aberto, abrigos sob rocha, casas subterrâneas e nas camadas superiores dos sambaquis fluviais), indicando se não sua associação com os períodos formadores dos sítios, sua presença na ocupação mais recente destes sítios. Também sabemos que estão dispersos em uma região de grande extensão (do sul do estado de São Paulo ao Rio Grande do Sul), com a predominância de floresta tropical (floresta ombrófila e ombrófila mista), cuja implantação representa uma conexão entre a planície costeira e as áreas do planalto, áreas que compõem o chamado território tradicional dos Laklãnõ (Xokleng). Podemos acrescentar a tais informações os dados arqueológicos e etnobotânicos que tem indicado um amplo conhecimento e manejo das plantas tanto das Matas tropicais quanto das Matas de Araucária pelas populações indígenas (Heineberg 2015; 
Cruz 2014; Noelli 1999/2000), a exemplo principalmente da Araucária (Reis et al 2014), mas também de outras plantas como as Goiabeiras, Jaboticabeiras, Butiás, entre outros, que foram apontados como tendo alta frequência, possivelmente devido a uma ação antrópica, em áreas de consideráveis extensões. No caso específico dos Laklãnõ (Xokleng), também as evidências etnohistóricas nos indicam um conhecimento de um amplo território, mas mais do que isto, o seu manejo através de indicadores de redes de caminhos e trilhas abertas e plantas conhecidas. Estes mesmos cronistas nos mostram a mobilidade destes povos, mas também nos relatam diversos indicadores de permanência seja em locais de moradia (aldeias, acampamentos recorrentes) seja na reutilização de espaços para atividades específicas, de caça, coleta, manejo e plantio.

Portanto se tomarmos os mesmos dados que muitas vezes são lidos como indicadores de uma certa polarização entre populações "caçadoras-coletores" X "horticultores com territorialidade fixa", temos indicadores de uma forma de apropriação do território particular. Se dissolvermos as categorias fixas, podemos pensar em ritmos de caminhar e parar, em ritmos de mobilidade e permanência específicos, que podem nos trazer valiosas informações sobre formas de criação de territorialidade como a conjunção de dados já publicados nos apontam.

\section{- o conhecimento territorial hoje}

Ao questionar os Laklãnõ (Xokleng) hoje sobre seu passado, de maneira geral a resposta é que quando eles eram "do mato" eles eram nômades. Resposta rapidamente dada pela grande maioria dos colaboradores da pesquisa. O termo "nômade" parece estar bastante enraizado no discurso Laklãnõ (Xokleng) sobre o passado. Mas como focar na mobilidade do presente com uma população que desde 1914, quando da formação do PI, foi forçadamente "aldeada"? Durante minha pesquisa na TI sobre território e memória alguns aspectos de sua relação com o território me chamaram particular atenção. O primeiro deles, é o que venho chamando de marcos, ou lugares de referência, mas poderiam ser lugares significativos (Zedeno e Bowser 2009), lugares de memória (Lane 2008) ou para usar uma fala Laklãnõ (Xokleng), aqueles lugares que "a gente dá nome”. Iniciei minha pesquisa sobre território a partir de um mapa da FUNAI que recentemente havia sido utilizado pelos alunos da licenciatura indígena da UFSC, para plotar novos locais, como demarcações políticas internas, áreas de cultivo, novas aldeias, cemitérios, entre outras coisas que podemos ver no mapa. Usei este trabalho como base para minhas interrogações na aldeia. Comecei perguntando onde havia sido o encontro com o Eduardo Hoerhann, onde eram as aldeias mais antigas, onde eram as áreas de cultivo e caça, etc. Aos poucos outros locais não plotados no mapa foram surgindo, principalmente acampamentos e aldeias antigas, que foram preenchendo um grande vazio que me intrigava. Mas além disto, durante minha estadia na aldeia no ano de 2013, ao perguntar sobre os lugares do passado no território alguns nomes diferentes surgiram, sendo que destes apenas um poderia ser visto na escala do mapa. Tratavam-se inicialmente de cinco nomes de lugares que foram descritos para mim como lugares de referência na paisagem. Lugares que todos sabiam onde eram, lugares que eram associados ao "antigamente", mas que como fui descobrir ainda eram lugares de "hoje". Portanto eles eram ou são referências ou marcos paisagísticos cuja localização, descrição e relação com eventos e pessoas do passado são passados de geração em geração e que não necessariamente as pessoas os visitam, mas, de maneira geral sabem onde fica. Copacãm Tschucambang, à época cacique regional da aldeia Figueira, me explica que é como você dizer para alguém na cidade "fica ali na esquina onde tem a farmácia”, querendo dizer tratarse de um nome específico no qual as pessoas conseguem identificar na paisagem. Da lista de lugares nomeados, três são na região da TI (entre os municípios de Ibirama e Doutor Pedrinho, Timbó e Itajaí), um fica mais ao sul no Rio Grande do Sul e um mais ao norte, provavelmente perto da fronteira do Paraná. 
Os lugares nomeados da paisagem também foram registrados por Cruz (2014):

\begin{abstract}
"Antes davam mais nomes para os lugares, pois eles andavam mais pelo mato. Quando eles davam nome era de acordo com as características do local para poder se comunicar e ter referências. O Óleo é onde tem a árvore de Óleo, e há outros locais com recursos e nomes como de animais também" (Mulher, 44 anos).
\end{abstract}

O uso de referenciais na paisagem é recorrente entre populações indígenas, especialmente aquelas conhecidas por sua mobilidade. Entre os Laklãnõ (Xokleng), como mencionado por Cruz (2014) e Heineberg (2014) as árvores $\mathrm{e}$, como veremos mais adiante, os marcadores topográficos como os paredões rochosos da serra, localmente chamado de "peiral", assumem um papel importante na nomeação de lugares significativos do território. Este aspecto foi observado por Pereira (1998) no Laudo Antropológico para a nova delimitação da Terra Indígena. Segundo Pereira (1998: 21) "São mencionados, também, acampamentos em locais em que se evidencia a presença de grandes árvores, como um pé de saputemo, imbuia, ou no meio dos pinheirais". Gostaria de chamar atenção especial ao Araçá Branco, nome de local mencionado diversas vezes ao longo da pesquisa. Referindo-se especificamente a este local, descrito como "acampamentos junto ao pé de araçá", Pereira relata que "Muitos Xokleng lembram que, ao passarem por ali, seus pais e avós apontavam e falavam a respeito da existência de tal referência significativa à reprodução física e cultural indígena" (1998: 21). Este autor cita diversas entrevistas entre representantes indígenas que se recordam e descrevem este lugar. Selecionei um deles para exemplificar um destes pontos de referência:

"Ali era, ali esse araçá é um lugar que mais conhecido ali porque era um lugar de se acampar, ficar tempos morando ali. $\dot{E}$ um lugar de moradia. Ali se reúne os índios, umas 2 mil indios, 5 mil indios se reúnem ali nesse local ali perto do araçá porque aquele aralá tempo de dar fruto vem muito passarinho, jacutinga, tudo isso, então se acampa ali perto para matar os passarinhos, né. É ali, né, e ali vem depois vem outros bichinhos, né (...) Então se acampava ali. No lugar que se acampava, vamos dizer é um lugar onde faziam a dança, a desta. O araçá é um lugar de se acampar e era perto e além disso é $i$, lugar onde se acampava para caçar aqio em roda desse. Se ia lá embaixo como lá pro Rio Dollmann, pra aquela banda lá pra Taió, mas outros ficavam por ali, depois voltava tudo aqui pra esse local (..) Eu me lembro, eu me lembro bem. Só que eu não sei qual é o tempo que derrubaram, mas eu, quando eu vim ali em 1938 ela já tava em pé ainda. Quarenta tava em pé, quarenta e dois por ali assim eu não sei mais se tava em pé ou não porque ai já tinha mais povoado (...) Que eu não vi mais foi em 1950, 52, 53, nunca mais vi. Só que pousei, parei de baixo (...) depois que derrubrarm também não sei qual pe o tempo.

Mas quem derrubou deve estar vivo, isto é interessante, né. Porque eles conheceram, então eles devem saber quem é que derrubou" Veitchá Téie (Apud Pereira 1998: 22).

O local é conhecido pelos moradores Laklãnõ Xokleng atuais como Kakupli, ou Araçá Branco. Pude visitar o local, que atualmente é uma área ocupada por colonos alemães que ali tem uma igreja rodeada por algumas casas. Trata-se de um local alto e plano onde outrora se encontrava uma grande árvore de Araçá Branco. Este local é constantemente visitado por vários Laklãnõ (Xokleng), que vão lá para "saber onde é". Dizem que ali é um lugar de "parada", de "morada, onde eles ficavam dias comendo quando dava fruto e muita casa. Era um lugar de encontro de muitos grupos".

O laudo antropológico indica o conhecimento do local pelos não indígenas que vivem no entorno, que indicam que ali era terra de índio, referindo-se inclusive a uma associação entre as plantas e os índios, conforme nos mostra Pereira (1998: 23) "Esse cepo de araçá, pelo que meu avô me conta, ele dizia que era o araçá dos índios. Era tudo respeitado, que era o araçá dos índios". Também entre as entrevistas com colonos não indígenas encontra-se uma referência temporal do local, como na 
fala "planta velha". O mesmo relatório indica relações fortes dos Laklãnõ com um grande pé de Saputemo na região de Bom Sucesso, além de inúmeras referências a locais de coleta de pinhão, presente tanto na memória dos indígenas quanto dos não indígenas que moram no entorno. Tais lugares nomeados foram utilizados para a remarcação da delimitação da terra indígena que está sendo pleiteado no STF, (indicado na figura 1 como aldeia antiga Cacuply ou no mapa da FUNAI como "aldeia do Araçá").

Outro lugar nomeado que pude identificar através de diversas falas dos Laklãnõ (Xokleng), foi Kóziklã, que fica na região de Timbó, município próximo, também no estado de Santa Catarina, e que significa "paredão da pedra furada" ou "paredão da pedra pintada". Dentre os entrevistados, alguns dizem já ter ido lá. Locais como estes, também foram chamados de pontos de encontro, por Kunding e Woie Kamlem. Marcos associados à pedras também foram relatados por Pereira (1998: 28) e foram usados na delimitação da TI, como podemos ver em diversas falas que indicam uma associação destes locais de pedra com locais de acampamento e moradia onde tinhas "barracas" e "ranchos" como na fala de Veitchá Téria e de Edu Priprá, relato no qual também indicam este ter sido o marco usado por Eduado Hoerhann na época dos primeiros contatos.

Outro nome mencionado ao longo da pesquisa foi "Kavig by txagtxa" a "montanha do rabo do tesoureiro". Como os outros lugares nomeados apresentados, este parece tratar-se de uma referência na paisagem, um "marco" que indicava um local onde as pessoas se encontravam e faziam seus acampamentos, festas e que precisavam receber nomes específicos para que fossem identificados.

$O$ fato de haver marcos nomeados na paisagem em si, não representa algo novo para nosso conhecimento acerca das populações indígenas. No entanto, a percepção do conhecimento destes marcos, destes referenciais paisagísticos

3 Os termos em Laklãnõ Xokleng foram conferidos por Caio Gakrán e Namblá Gakrán. Os termos transcritos que não foram reconhecidos serão indicados no texto. me chamou particular atenção tendo em vista a situação atual dos Laklãnõ (Xokleng) que no ano de 2014 "comemoraram" 100 anos da chamada "pacificação" e com ela o chamado "sedentarismo" ou aldeamento. O que nesta situação específica chama atenção é este tipo de conhecimento ter se mantido, mesmo que apenas na memória em alguns casos, após uma intensa desestruturação social e cultural e após o seu sistema de mobilidade e com isto também formas de organização sócio-políticas específicas terem sido radicalmente tranformadas. Poderíamos entender este aspecto do território a partir da 4a dimensão proposta por Politis (2007), os "lugares conhecidos", que seriam, segundo este autor para os Nukak da Colombia "lugares que os Nukak sabem da existência, mas nunca ou muito raramente vão de fato. Esta paisagem de fora é conhecida pelo fluxo de informações entre os bandos e a partir de informação oral, não através da experiência direta. Nesta categoria são incorporados os territórios ocupados antigamente pelos ancestrais, incluindo os locais conhecidos através de sua história oral como sendo sua terra originária”.

Em uma outra entrevista, quando perguntado sobre estes locais, S. Woie Camlém me disse fazerem parte da chamada "história da pacificação, ou melhor de antes da "história da pacificação". Cito apenas um trecho da entrevista, onde ele cita estes locais:

Kavig by txagtxa, é de lá que Kuzug e a equipe dele, e a família dele, veio para cá no caminho. Onde era o caminho do avó dele. De lá que eles vieram para pacificar com esse Eduardo. Desceu ali na D'albergia, naqueles paredões, é lá que ele morreu o Zetxa. Fizeram matança ali e depois queimaram ele e depois vieram de novo lá na montanha no Serra Verde, lá no Taió Grande. (...) Ai eles disseram vamos de volta, vamos fazer um atalho naquele ribeirão forte, grande que é ali. Vamos descer lá que tem uma roça dos brancos, vamos lá tirar um machado para mim. Eles vieram ali.

Ai chegaram no dia 20 de setembro e pousaram no dia 21 e desceram para cá. Ele mandou sua familia inteira, Kóvi, Voble, que não é seu irmão, é seu companheiro. 

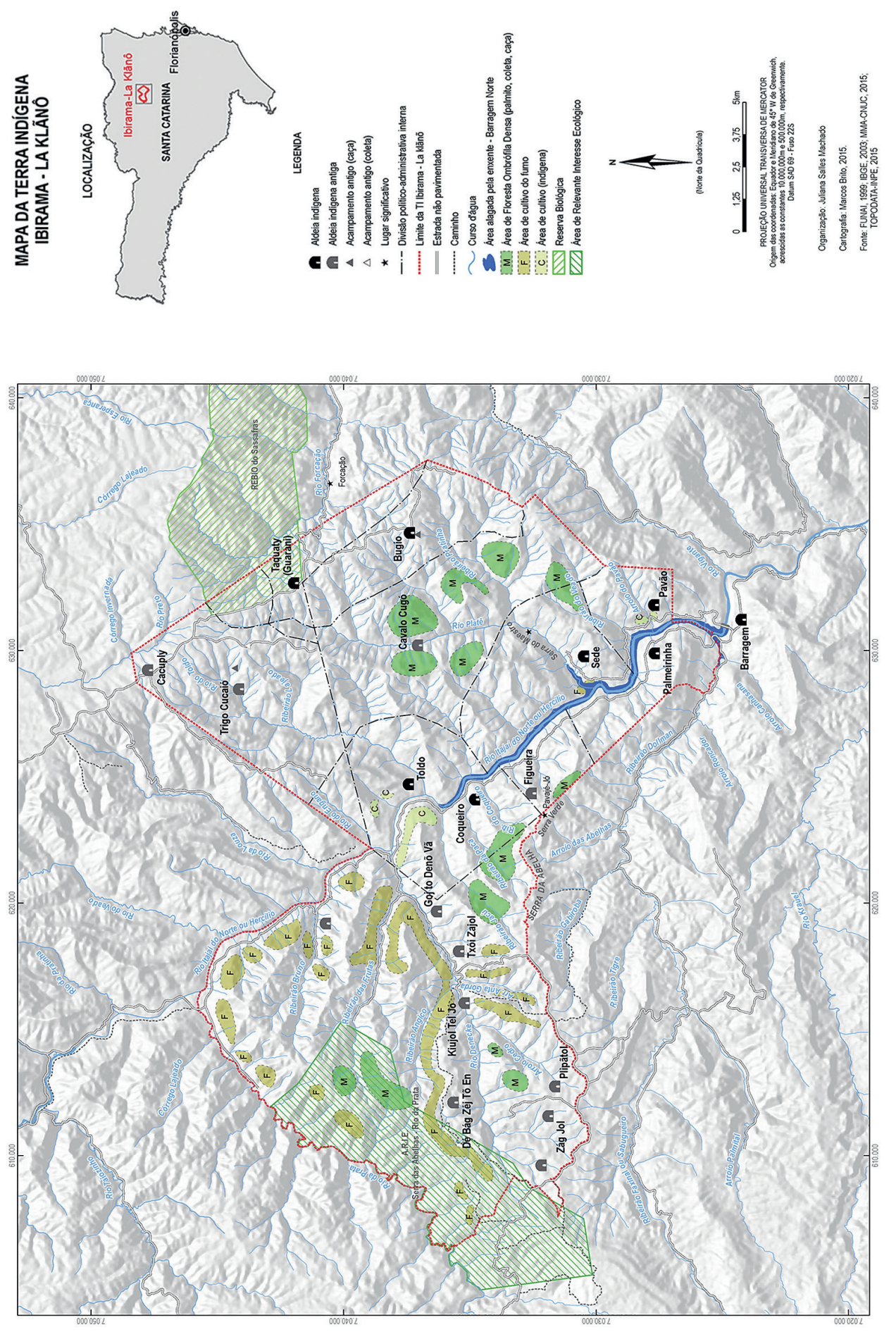

Fig. 1. Mapa da terra indígena Ibirama - Laklãnõ. 
Eram 2 irmãos, 3 corajosos companheiros: Copãcãm, Kóvi e Voble. Desceram lá onde era a casa dele, mas eles estavam no meio da roça que era grande. Era dia 20 que desceram lá, foram lá e viram que a roça tava no meio do campo. E ai acharam que era dificil e voltaram para o acampamento e falaram para o pai: "pai, lá é a roça dele. Não tenho coragem de chegar lá, não tem como entrar lá. No outro dia o pai disse: "vai de novo e vê se vocês acham um outro jeito de entrar lá". Eles foram lá. E de longe eles viram e eles ficaram na beira do mato, num cepo, cairaran, e ficaram atrás do cepo grande.

Eduardo estava no meio da roça conversando com os amigos dele. De certo estava contando que eles estiveram aqui. Ai gritaram para ele, se ele tinha levada as roupas, as foices, o facão. Daqui a pouco Kóvi disse para Voble gritar para ele.

Kóvi disse tu grita e Voble gritou e Eduardo gritou e chamou e falou que ele tem as roupas, tudo ele oferecia para ele. Aí ele ficou convidando, convidando, chamando, foi e foi. Quando, era meio dia eles ele começaram a falar assim: vamos la pegar o que ele esta oferecendo. Kóvi disse para o Eduardo: "bota mais para cá, bota mais para longe não fica perto". Ai ele se retirou, Eduardo se retirou. Ai ele veio conversando, o Voble tava junto, Voble disse vai tu pegar, se ele te matar eu vou te cobrar, agora tu não, eu vou te espiar. Mas quando ele viu, veio atrás também. Mas tinha um amigo que veio assim escondido, que veio escondido, ele não se mostrou com ele, ele veio atras dele. Quando ele estava quase chegando ele jogou uma flecha para ele, queria matar ele. Mas a flecha não chegou, caiu longe dele. Eduardo saiu. Descen toda a turma que tava com ele e foram lá.

Voble foi na casa dele. Acharam machado, comida, tinha porco, mataram porco e levaram tudo. No dia seguinte, dia 22, eles desceram de novo, eles vieram porque uma mulher pediu para ele ir lá buscar aquele cachorro para mim. De madrugada ele convidou o Kóvi, "vamos lá para esta senhora que quer cachorro".
Agora é dia. Ele veio, chegou, viu o cachorro depois andaram perto por ai. Daqui a pouco, Eduardo estava voltando com a turma dele. Quando a turma dele estava voltando com os gado e o resto estava voltando de canoa. Quando estava andando perto da casa deles, escutam tiro. "Escutaram o tiro?, sim, escutaram mais dois tiros. Estavam vindo perto, sairam da mata e ficaram atras do cepo grande de novo olhando.

(...)

Cruzaram o rio que tava baixinho e convidaram vamos gritar de novo para ele. Voble veio de novo e voltou. Gritou alto, chamou de novo. "Vim trazendo mais roupa para ti, mais roupa, mais ferramenta, facão, tudo". Voble mandou Kóvi de novo, vai tu lá.

Kóvi veio gritando para ele de novo. Traz mais para cá e fica longe. Ele deixou e ficou longe. Kóvi: se eu vou lá tu quer me matar com sua turma.Eduardo disse não, eu estou te chamando para você vir para ficar aqui com nós. Vinha conversando. Voble veio atras dele e chegou nele. Ele pegou a mão dele e depois a do Voble também.

Ai a turma do Eduardo batia palma. "Cade o resto da turma?" "Eles tão lá no mato". "Vai chamar ele e vou matar um gado para ti". Aí, pegaram a mão dele e depois voltaram e Voble disse amanhã eu vou trazer a turma, dia 22 de setembro.

No dia seguinte trouxe todo o resto da turma, a mulherada ficou com medo e ficou na beira do mato. Eduardo chamou vem, vem comer carne. Voble ajudou a chamar, até que todo mundo veio. As mulheres e companheiros deles vieram.

Woie Kamlém (2013)

Em outra ocasião S. Woie retomou a "história da pacificação", da qual cito alguns trechos:

Ã txe ke vy $y^{4}$ serra do funil, de lá que eles vieram para pacificar, desceu ali no dalbergia no paredão (...) morre, fizeram uma dança e quei-

4 Termo não reconhecido. 
maram ele. De lá foram para a montanha em taio grande, Kle tõ zunh - montanha que foram depois da morte Subiram em cima e avistou o araça com a turma dele. "vamos nessa direção até o Kakupli porque camos comer jacutinga e os passarinho" desceram, fizeram uma dança, uma festa. Cruzaram esse rio grande até o Kakupli. Pararam lá e fizeram rancho. Eles vem ficam comendo e depois vai em outrs direção. Kozum convidou a turma "vamos lá para Juazylã", o paredão pintado, vamos nessa direção, dai eles foram. Quando eles chegaram lá, ficaram uns dias lá e depois vamos de volta. Mas vamos cortar viagem, vamos pegar um atalho por um ribeirão forte, um ribeirão grande. Lá tem uma roça dos brancos, lá tem um machado, vamos lá pegar. Chegaram no dia 20 de setembro e pousaram uma noite. Mandaram a familia dele, Voble, Kópaká, Kóvi. Desceram lá onde era a casa dele, no meio da roça, a roça era grande. Viram que a casa ficava no meio da roça e acharam dificil. Jug (pai) apontem a casa dele, não tem coragem, não tem como entrar lá. No outro dia o pai disse> vai de novo e veja se conseguem achar um meio de entrar lá. Eles foram lá, na beira do mato, atras do cepo grande, eles viram eles. Eduardo estava lá, no meio deles, apontando. Gritaram para ele. Eduardo tinha levado machado, roupa, facão, comida. Kóvi disse para Voble gritar para ele. Eduardo também gritou e disse que tinha coisas para ele. Tudo ele oferceria para eles.

Outro colaborador, S. Alfredo, menciona também esta caminhada e suas paradas. Nesta última entrevista onde conta também a "história da pacificação”, S. Alfredo indica algumas de suas localizações, que como posteriormente pude perceber estavam representadas no mapa da FUNAI como "aldeias transitórias" (identificadas na figura 1 como aldeias antigas ).

Cito a entrevista de S. Alfredo realizada na Aldeia Bugio em 2014 sobre as caminhadas Laklãnõ (Xokleng):

"Eles vieram do Mato Grosso. Os antigos contaram para mim. Eles vieram do Mato Gros- so para o sul. Sentiram falta de algum alimento. Foram feitas três reuniões e vieram de lá pra cá. A morada deles fica lá em Kle julho bág, Ponta Grossa, Paraná. Vieram acampar perto. Levaram 1 ano do Mato Grosso para o sul. Plõg pil tén ku ki jul mu6. Falaram para mim. Kle julho bág. Como é que foi? Sairam de lá na época do pinhão, quando vieram pela mata acabaram o pinhão. Mas sabemos que levaram um ano para acampar lá. Não tinha branco nenhum, veio três turmas de lá. Uma turma veio a frente, depois mais um ano, mais uma turma, e mais um ano, mais uma turma. Uma turma foi para o Rio de Janeiro, uma para o Rio Grande do Sul e uma veio para Paraná e Santa Catarina. Não se sabe quantos homens. Hoje estamos aqui. Hoje é mudado o nome, o apelido de Laklãnó (Xokleng). O nome da tribo que eu sei é Bororo. Também estudei isto com o chefe do posto. Começaram a dividir em partes e foram acabando. Os brancos mataram todos eles em São Paulo. Dos Bororo não sobrou ninguem. A mortandade dos indios. Rio Grande a mesma coisa, para baixo de Caxias do sul (nosso). Outra nossa aldeia que foi esquecida - Campos Novos, também é nosso. Aqui em Santa Catarina os indios começaram a andar até que viram que os brancos tão vindo, ninguém sabe quantos anos. Iam para São Paulo e voltavam de lá. Caminho de Porto Alegre para São Paulo, caminho de Santa Cecilia. Os brancos estão envadindo a terra. Vivia no mato, eles são natural do mato, são nativo. A Sociedade diz que madeira é nativa e os indios são maltratados. A história antiga abrange hoje a história nova. O indio não conhece remédio, indio morre de velho ou morre acidentado. Parte do meu tataravó, a história disse para mim. Estava fazendo os deveres deles, velhinho, morreu. Se ele anda bem velhinho, o fígado dele com cai e ele morreu. Então não tem doença no mato. Tudo o ue sei é que tudo isto é depois do diluvio. A história vindo de lá, em minha mente foi olhar. Pela bíblia não tinha branco porque todo mundo falva uma lpingua e depois da desobediência é que existiu a nação. $\mathrm{O}$ indio se faz diferente. Buscaram os indios. A história disse que o indio 
é o verdadeiro brasileiro, o dono da nação. A história verdadeira, como vieram do Mato Grosso e vieram para Ponta Grossa. A FUNAI ganha na conta dos indios. Não deram valor ao primeiro acampamento em Ponta Grossa, um mato grande, podia ter uma reserva lá. Os indios vivia na divisa Santa Catarina, tudo eles conhecem, não ficavam parado. No museu do Eduardo tem uma lança de ferro do meu avô. Ali (em São Paulo) é o lugar dele. Nculabé7- nome da cidade é idioma do indio. Quem caçando o indio, sempre escuta o nome dos indios. Corupá, Curitiba (traga a roupa velha para mim em indígena), muitos nomes por ai é idioma indígena. Nos lembramos de explicação deles".

"Convive com dois indios velhos que foram pacificados - Kovi e Voble. Em 1950 iam jogar futebol em Timbó e mostraram a divisa da terra. Três rapazes que morreram. O pai dele que mostrou a divisa da terra. Como ele saia para fora, lá os brancos já estavam no mato, os fazendeiros, em Santa Cecília, tudo no lugar dele. $\mathrm{O}$ tempo que eu fui pacificado já tinha fazendeiro no monte castelo. Martim bugreiro pago pelo governo ia acabar com eles. Em 1917 o padre deu para ele o livro. No rio Platê, o padre veio fazer o batismo, eu batizei em 1994, não cobrei porque sei que estou morando na reserva deles, Paraguaçu"

"como os indios foram massacrados desde o príncipio. Muitos antes do Martinho bugreiro. Indios mataram um bugreiro antes. Teve indenização para a mulher dele pago pelo governo. Primeiro matador de indio era o coronel mandado pelo D. João sesto, logo depois que descobriram o brasil, desde aquela época já tinha levado eles como bicho. Assim fizeram com a nação, encontraram o bicho no mato e vai atrás para mater e correr. Esconderam vinte soldados que os indios mataram e não se sabe quantos indios morreram. Querem acabar com os indios até hoje."

"quero mostrar a divisa de nossas terras para o cacique. Outra reserva, muncipio de Taió

7 Termo não reconhecido está dentro de nossa reserva. A divisa da terra é o indio mais velho, se ele diz que passa lá é lá. $\mathrm{O}$ indio vive com pesca e caça. $\mathrm{O}$ indio não pode matar nada, não pode viver como indio. É contra lei, desarmar o indio. O Laklãnõ (Xokleng) tá oprimido, é isto que eu estou falando. Lei do indio, FUNAI disse, mas é mentira. Os indios tão sofrendo, saúde. Estamos hoje completamente mal tratados. A vida nossa aqui não é bom"

(...)

"Eles não sabiam o que é medo. Eles sabiam que existe cobra e tigre do mato. Uma distância daqui e Blumenau, daqui até lá, é um pulo. Foi de mão abanando, depois se lembrou que ele esqueceu sua lança, então veio de volta e pousou no mato sozinho, sozinho contando as horas da noite. Tigre escutou ele, o tigre olhou e ele foi correndo em cima do tigre assim de mão leve. O tigre correu dele. $\mathrm{O}$ indio morre mas sem medo.

Antes era Bororo. 1914 com botoque comprido, apelidado botocudo. 1964 mudou para Laklãnõ (Xokleng) pelo Silvio Coelho. Eu já conversei com Bororo e consegui entender a lingua.

Foram caçar com Bororo, foram lá para ver se é terra grande, conheceram 1 ano e não acabaram a terra e chegaram em ponta grossa. Duas serras compridas, duas juntas, como rabo de passarinho, próximo a florianopolis. Kavig by txagtxa, paradeiro, nome daquele lugar em florianopolis.

Indio plantava milho purunga, abobora. Macetava o mato com pau e deixava todas as madeiras gordas em pé para poder plantar. Até que P. Alvares Cabral para o Brasil, viram que tinha ferro para cortar."

É importante percebermos alguns elementos que estruturam estas narrativas. Os nomes dos lugares assumem aqui um elemento importante da memória realizando um duplo efeito de marcadores de memória do ritmo e sequência da narrativa, assim como referências de veracidade da mesma. São nomes cujos significados são compartilhados culturalmente 
e remetem a uma memória coletiva de um passado que continua sendo resgatado no presente. Eles aparecem nestas narrativas como elementos importantes de percepção da paisagem para os antigos, como marcadores simultaneamente do tempo e do espaço. São marcos que ao mesmo tempo individualizam os lugares por atribuirem a eles uma localização específica no espaço, uma expectativa de atividade e uso definidos (lugar de caçar jacutinga, comer frutos, fazer festa, encontrar os grupos) e também podem servir como marcos relacionais, pois interligam os espaços conhecidos do território e os articulam em um sistema, rede ou comunidade de lugares. A partir desta percepção relacional do espaço, sabe-se a distância e o tempo da próxima caminhada, assim como o tempo que já passou. Estas características parecem ter importância para esta população como podemos notar nas formas características de contar histórias, nas quais a relação tempo-espaço são sempre ressaltadas (como também foi observado por Cruz 2015 sobre as formas de linguagem Laklãnõ (Xokleng)), além de possuirem expressões específicas para descrever a relação tempo-espaço. Este é o caso de "Pãvanh jó", por exemplo, expressão utilizada para se referir a "mirada" que se tem de alguns lugares, dos quais podemos avistar ao longe, vários lugares conhecidos.

Outro aspecto importante que podemos ressaltar nestas narrativas são o fluxo, o ritmo desta mobilidade, na qual não se trata de um contínuo movimento, mas sim de um ritmo de caminhada e parada que só podem ser pensados de forma articulada. Assim, os caminhos e as paradas são fundamentais para os Laklãnõ (Xokleng) e podemos ver sua importância em um de seus mitos de criação:

\footnotetext{
A geração do homem Kânhâhã Nãnblá (Santos 1997:151)

Há duas formas da geração do homem

Os Kledo sairam da Montanha

E os Vajeky sairam da água (provavelmente da água do mar)

Eles queriam sair e ficaram esperando do lado de baixo da água

Enquanto isso Plandjung veio subindo, fazendo caminho
}

E quando terminou de fazer caminho, voltou para buscar os outros

Então vieram subindo com ele.

Onde pisaram em terra, preparavam lugare

festejaram dançando

Enquando isso, Plandjug continuou fazendo caminho

Então eles vieram atrás dele, e novamene pararam para festejar.

Nisso, ouviram de outros homens, que vinham atrás, e o Vajeky ficou com medo.

Então Vajeky fez para sua criação uma onça

E o Zágpope Paté pintou a onça para ele.

No pescoço, deixou marcas pintadas de forma arrendonda fechada, outras compridas.

O Zezé pintou com marcas cumpridas e umas circulares, na paleta da onça.

E Txu Txuvanh pintou nas costas marcas circulares arredondadas fechadas.

E eles acabaram de pintar a onça Vajekym que ele criou.

E ele disse: minha criação agora grita do jeito que quiser.

Então ele gritou e foi atrás dos outros, para comê-los.

Agora a pintura (marca) do Zagpope Paté é arredondada fechada e umas compridas.

E a pintura do Zezé agora é comprida e umas circulares.

E a pintura do Txu Txuvanh agora é circular e outras arredondadas fechadas.

Agora a geração deles usa pintura (marcas) de seus pais.

(Markus 2009: 66 apud Santos 1997)

Outro mito da geração do homem coletada por Markus em 2002 traz novamente a caminhada e a parada como elementos estruturantes da cultura Laklãnõ (Xokleng):

"Segundo a lenda Xokleng sobre a geração do ser humano, sabemos que há duas formas de geração. Uma saiu da montanha e a outra da água do mar... conta a lenda que na vontade de sair, mas com muito medo, o chefe vãjeky, manda um dos membros da comunidade sair para investigar a terra e trazer uma amostra do lugar para ele. Este homem vai e vê as aves e pensa: "vou levar um desses pássaros para meu chefe". 
Surge então o arco e a flecha com os quais o ser humano mata um gavião e traz para o seu chefe. O lider fica contente, mas inseguro, envia outros seres humanos, os quais também trazem amostras do lugar dando, assim, segurança ao povo que saiam da água para uma nova terra. Ao saírem da água, todos comemoram a chegada e, durante as comemorações, eles ouvem um barulho de outras pessoas e ficam aterrorizados, sem saber o que fazer. Então o chefe tem uma ideia: "vou criar uma onça", diz. Manda que seja derrubada uma árvore e do tronco dessa árvore faz uma onça, surge então a arte de esculpir. Depois da onça pronta, ele pede que ela seja pintada. Surge ai a arte de pintar e mais as marcas tribais que vai acompanhar todas as outras gerações até os dias atuais. Nesse primeiro momento as cores não são uma preocupação, por isso só é usado o preto. As outras cores só são observadas nas paisagens naturais. As cores dos pássaros surgem a partir de uma outra lenda, a do beija-flor que escondeu a água. Diz a lenda que na época em que só se encontrava mel em rochas, os pássaros e outros animais não se alimentavam com essa substância. Um dia os pássaros encontraram uma colmeia em uma taipa e todos tentavam furar o rochedo para tirar o mel, mas não eram felizes, pois seus bicos acabavam se quebrando com o impaco e o sangue escorria em seus corpos, manchando-os, dando assim suas cores, pois não tinham água para lavá-los. Essa lenda é muito importante dentro da arte, porque os Xokleng, ao longo de sua caminhada, começaram a usar as penas em seus cocares, artesanato usado pelos velhos chefes guerreiros. Também se usava e usa-se em arcos e fechas, nesse último para dar direção. As mulheres por sua vez, usavam penas de pássaros em brincos, colares, pulseiras e enfeites nas pernas e braços. A necessidade de conduzir os alimentos nas andanças dos Xokleng faz surgir a cestaria. Já a vestimenta e cobertores com fibra de urtiga surgiram a partir das baixas temperaturas de certas regiões por onde passavam. A necessidade de cozinhar alimentos, ou esquentar água fez surgir a cerâmica, ou arte de fazer panelas e outros objetos de barro. Esses conhecimentos foram passando de geração em geração até surgir a tal "pacificação" e destruiur quase toda a cultura Xokleng” (Markus 2006: 36)

Há cem anos os Laklãnõ (Xokleng) são conhecidos pela ausência de seus caminhos, os mesmos que chamaram tanta atenção dos "Zug" (brancos). No entanto, ao percorrer as trilhas no território em busca do preenchimento dos vazios no mapa pensando tratar-se de locais de aleias antigas, percebemos que estas aldeias abandonadas, são até hoje utilizadas (como já nos indicava Posey para descrever lugares abandonados entre os Kayapó). Para citar apenas um exemplo, durante três meses, três famílias acamparam em uma destas aldeias em busca de taquara para seu artesanato no ano de 2014. Também na época de pesca era comum (até poucos anos atrás quando a barragem não havia causado tanto estrago no seu entorno), os Laklãnõ (Xokleng) acamparam vários dias ou até semanas para pescar junto com sua família. Simião me conta que quando era pequeno, antes da obrigatoriedade da presença na escola, era comum as famílias se dividirem e alguns ficarem na aldeia de baixo enquanto o pai ou a mãe com alguns filhos e outros amigos e parentes e acampar em outras áreas para tirar palmito. $\mathrm{O}$ impacto da obrigatoriedade da escola parece ter sido um elemento forte para uma nova mudança nas formas de mobilidade Laklãnõ (Xokleng).

Assim, a existência de uma aldeia mais fixa e permanente não parece ser contraditória a formas relativamente altas de mobilidade de grupos menores que podem juntar-se ou não em busca de recursos específicos, para fazer festa, ou para "fazer caminho". 
MACHADO, J.S. Paths and Stops. Perspectives on Laklãnõ (Xokleng) territory. R.

Museu Arq. Etn., 27: 179-196, 2016.

\begin{abstract}
One hundred years after the first Xokléng/Laklanõ forced settlement of the Santa Catarina State we see an intense social and political movement between this indigenous population. Committed with a project to the strengthening of their ethnic identity the Xokleng / Laklanõ has sought in history, in the past and in their memory a path for their future. Since at least the 1970s this indigenous population has participated in the production of scientific knowledge as partners in several studies. Their memory is woven from threads of oral history and academic speeches from different disciplines along this contact path. Today they are inserted in the academic environment and have been building a cultural project for them people based on a complex tangle of knowledge and wisdom that go beyond the boundaries between local-global, emic-ethical, native knowledge scientific knowledge. In this article I intend to reflect about our own constructions and practices in archaeological research from the perspective of the work done by indigenes scholars of the past-present axis.
\end{abstract}

Keywords: Laklãnõ; Memory; Ethnic identity; Knowledge; Academic indigenes.

\title{
Referências Bibliográficas
}

Balée, W. 1994 Footprints of the Forest: Ka'apor Ethnobotany-the Historical Ecology of Plant Utilization by an Amazonian People. New York: Columbia University Press.

Binford, L. 1978 Nunamuit Ethnoarchaeology. New York: Academic Press.

Binford, L. 1983 In pursuit of the past: decoding the archaeological record. New York: Academic press.

Binford, L. 1982. Archaeology of Place. Journal of Anthropological Archaeology, 1(1): 5-31

Claudino, D.C. 2011. Arqueologia na Encosta Catarinense: em busca dos vestígios materiais Xokleng. Dissertação de Mestrado em História. UNISINOS, São Leopoldo/RS.

Colwell-Chanthaphonh, C. e Ferguson, T.J. 2008. Collaboration in Archaeological Practice. Engaging Descendent Communities. Altamira Press: New York.
Conceição, L.C. 2015. Vivências de escritas entre os Laklano/Xokleng. Dissertação de Mestrado em Antropologia Social, Universidade Federal de Santa Catarina, Florianópolis.

Cortelletti, R. 2012. Projeto Arqueológico Alto Canoas - PARACA. Um estudo da presença Jê no Planalto Catarinense. Tese deDoutorado em Arqueologia, Museu de Arqueologia e Etnologia, Universidade de São Paulo, São Paulo.

Cruz, T.M.S. 2014. Etnoecologia de Paisagens na Terra Indígena Ibirama Laklãnõ, Santa Catarina, Brasil. Dissertação de Mestrado em Ecologia Universidade Federal de Santa Catarina, Florianópolis.

De Masi, M.A.N. (Org.). 2006. Xokleng 2860 a.C. As Terras Altas do Sul do Brasil. Transcrições do Seminário de Arqueologia e Etnohistória. Ed. Unisul, Tubarão. 
Dias, A.S. 2003. Sistemas de Assentamento e estilo tecnológico. Uma proposta interpretativa para a ocupação pré-colonial do Alto Vale do Rio dos Sinos. Tese de Doutorado em Arqueologia, Museu de Arqueologia e Etnologia, Universidade de São Paulo. São Paulo.

Dove, M. e Carpenter, C. (Orgs) 2008. Environmental Anthropology. A Historical Reader. Oxford: Blackwell.

Eble, A.B. 1973. Problemas Arqueológicos da Região do Alto Vale do Itajaí. Anais do Museu de Antropologia, Universidade Federal de Santa Catarina. Florianópolis.

Fairclough, G.; Harrison, R.; Jameson, J.; Schofield, J. 2008. The Heritage Reader. Routledge, New York.

Farias, D.S.E. 2005. Distribuição e Padrão de Assentamento - Propostas para os Sítios da Tradição Umbu na Encosta de Santa Catarina. Tese de Doutorado em História, Faculdade de Filosofia e Ciências Humanas, PUCRS, Porto Alegre.

Fossari, T.D. 2004. A população pré-colonial Jê na paisagem da Ilha de Santa Catarina. Tese de Doutorado em Geografia, Universidade Federal de Santa Catarina, Florianópolis.

Gakran, N. 2005. Estudo da Morfossintaxe da Lingua Laklãnõ/Xokleng Jê. Dissertação de Mestrado em Linguística. UNICAMP, Campinas.

Heineberg, M.R. 2014. Conhecimento e Uso das Plantas pelos Xokleng na TI Ibirama Laklãnõ, Santa Catarina. Dissertação de Mestrado em Biologia, Universidade Federal de Santa Catarina, Florianópolis.

Knapp, A.B. \& Ashmore, W. (Eds.) 1999. Archaeologies of Landscape. Contemporary Perspectives. Londres: Blackwell Publishers.

Lane, P.J. 2008. The use of Ethnography in Landscape Archaeology. In David, B. and
Thomas, J. Handbook of Landscape Archaeology. Walnut Creek, CA: Left Coast Press, pp. 237-244.

Lavina, R. 1994. Os Xokleng de Santa Catarina: Uma Etnohistória e Sugestões para os Arqueólogos. Dissertação de Mestrado em História. Universidade do Vale do Rio dos Sinos UNISINOS. São Leopoldo.

Machado, J.S. 2015. Ũ TÕDÉN TXI KABEL. aqueles que contam histórias.memória e território Laklãnõ (Xokleng). Relatório PosDoutorado FAPESP, Museu de Arqueologia e Etnologia, Universidade de São Paulo.

Machado, J.S. 2012. Lugares de gente: mulheres, plantas e redes de troca no delta amazônica. Tese de Doutorado em Antropologia, Museu Nacional, UFRJ, Rio de Janeiro.

Nigro, C. 2004. Para além das correrias. Desafio socioambiental no Alto Vale do Itajaí. In Ricardo, F. Terras Indigena $\mathbb{E}$ Unidades de Conservação da natureza. O desafio das sobreposições. ISA, São Paulo, pp. 333-356.

Noelli, F.S. 1999-2000. A Ocupação Humana na região sul do Brasil: Arqueologia, debates e perspectivas 1872-2000. Revista USP, (44) 218-269.

Noelli, F.S. 1999. Repensando os rótulos e a hstória dos Jê do Sul o Brasil a partir de uma interpretação interdisciplinar. Revista do Museu de Arqueologia e Etnologia, São Paulo, Suplemento 3: 285-303.

Noelli, F.S. 1996. Os Jê do Brasil Meridional e a antiguidade da agricultura: elementos de linguística, arqueologia e etnografia. Estudos Ibero-americandos, XXII (1): 13-25.

Noelli, F.S. 2004. O mapa arqueológico dos povos Jê no sul do Brasil. In Tommasino, K.; Mota, L.T.; Noelli, F.S. Novas Contribuições aos estudos interdisciplinares dos Kaingang. Eduel, pp. 17-56. 
Paula, J.M. 1924. Memória sobre os botocodos do Paraná e Santa Catarina organizada pelo serviço de proteção aos selvicolas sob a inspeccao do Dr. José Maria de Paula. Annaes do XX Congresso Internacional de Americanistas. Rio de Janeiro.

Pereira, W.S. 1998. Laudo antropológico de identificação e delimitação de terra de ocupação tradicional Laklãnõ (Xokleng): história do contacto, dinâmica social e mobilidade indígena no Sul do Brasil. Porto Alegre: Funai.

Piazza, W.F. 1967. Nota preliminar sobre o PRONAPA no estado de Santa Catarina. PRONAPA, Publicações Avulsas no 6, Museu Goeldi, Belém.

Politis, G. Nukak. Ethnoarchaeology of an Amazonian People. Left Coast Press, 2007

Posey, D. [1987] 2008. Indigenous Management of tropical Forest Ecosystems: the case of the Kayapós Indians of the Brazilian Amazon. In Dove, M. R. e Carpenter, C. (Eds) Environmental Anthropology. A historical reader, Blackwell, pp. 89-101.

Reis, M.S.; Ladio, A.; Peroni N. Landscapes with Araucaria in South America: evidence for a cultural dimension. 2014. Landscapes with Araucaria in South America: evidence for a cultural dimension. Ecology and Society 19(2): 43.

Reis, J.A. 2002. Arqueologia dos buracos de bugre: uma pré-história do planalto meridional. EDUCS.

Santos, S.C.dos. 1979. O homem índio sobrevivente do Sul: antropologia visual. Florianópolis: Ed.Garatuja.

Santos, S.C.dos. 1973. Índios e brancos no sul do Brasil: a dramática experiência dos Laklãnõ (Xokleng). Florianópolis : Edeme.

Santos, S.C.dos. 1963. Os Grupos Jê em Santa Catarina : projeto de pesquisa. Rio de Janeiro (RJ): [s.n.].
Santos, S.C.dos. 1965. Os índios Laklãnõ (Xokleng) e o antropólogo. Natal: Universidade do Rio Grande. 1965 Os Laklãnõ (Xokleng), hoje. Blumenau: Blumenau em Cadernos.

Santos, S.C.dos. 1966. Sobre a organização social dos Laklãnõ (Xokleng). Florianópolis: UFSC.

Schmitz, P.I.; Becker, I.I.B. 2006. Os primitivos engenheiros do Planalto e suas estruturas subterrâneas: a tradição Taquara in: Schmitz, P.I. (Ed.). Arqueologia do Rio Grande do Sul, Brasil, Documento 05, São Leoplodo: IAP - UNISINOS, pp. 65-99.

Schmitz, P.I.; Arnt, F.V.; Beber, M.V.; Rosa, A.O.; Rogge, J.H. 2009. Taió, no Vale do rio Itajaí, SC. O encontro de antigos caçadores com as casas subterrâneas. Pesquisas (Antropologia), 67: 185-320 São Leopoldo: Instituto Anchietano de Pesquisas.

Silva, F.A. \& Noelli, F.S. 1996. Para uma síntese dos Jê do sul: igualdades, diferenças e dúvidas para etnografia, etnohistória e arqueologia. Estudos Ibero-americanos, XXII (1).

Silva, F.A. 2011a. Arqueologia como tradução do passado no presente. Amazônica 3(2): 260-267.

Silva, F.A. 2011b. Patrimônio Arqueológico em terras indígenas: considerações sobre o tema no Brasil. In Ferreira, L.M.; Ferreira, M.L.M.; Rotman, M.B. (Orgs.) Patrimônio Cultural no Brasil e na Argentina. Estudos de caso. São Paulo: AnnaBlume/CAPES, pp 189-214.

Silva, F.A. 2012a. Arqueologia e gestão do patrimônio Arqueológico: a teoria arqueológica e o papel do arqueólogo. IPHAN, no prelo.

Silva, F.A. 2012b. O passado no presente: narrativas arqueológicas e narrativas indígenas. In Ferreira, L.M. Multivocalidade, no prelo.

Urban, G. 1985. Interpretation of inter-cultural contact: the Shokleng and Brazilian na- 
tional society 1914-1916. Ethnohistory, 32(3): 224-44.

Veiga, J. 2004. Aspectos Fundamentais da Cultura Kaingang. Editora Curt Nimuendaju.

Wittmann, L.T. 2007. O vapor e o botoque: imigrantes alemães e indios Xokleng no Vale do Itajai/SC (18501926). Florianópolis: Letras Contemporâneas.

Zedeño, M.N. 1997. Landscapes, land use and the history of territory formation: an ex- ample from puebloan southwest. Journal of archaeological method an theory, 4 (1): 63-103.

Zedeño, M.N. 2008. The Archaeology of Territory and Territoriality. In David, B. and Thomas, J. Handbook of Landscape Archaeology. Walnut Creek, CA: Left Coast Press, pp. 210-217

Zedeño, M.N. \& Bowser; Brenda, J. (Eds.) 2009. The archaeology of meaningful places. Salt Lake: University of Utah Press. 